\title{
ALGUNAS OBSERVACIONES CRÍTICAS AL TRABAJO DE ENRIQUE P. HABA*
}

\author{
Óscar Sarlo ** \\ Universidad de la República (Uruguay)
}

RESUMEN. El autor considera que la crítica que HABA efectúa contra la teoría estándar de la argumentación es acertada "en la mayoría de los casos», pero no tiene en cuenta algunos aspectos relevantes que permitirían atribuirle cierto valor. En particular, SARLO considera la posibilidad de entender esa teoría como un tipo ideal en sentido weberiano; o de partir de la distinción entre contexto de descubrimiento y contexto de justificación para rescatar al menos una cierta dimensión de «racionalidad argumentativa». Por lo demás, SARLO comparte con HABA la posibilidad y conveniencia de «disponer de una teoría de la argumentación en sentido descriptivo/explicativo»; el principal obstáculo epistémico para ello, en su opinión, radica en la «pereza intelectual» de muchos académicos, poco dispuestos a «reflexionar sobre su propia realidad, como demandaría una teoría jurídica sensible a los hechos».

Palabras clave: argumentación jurídica, E. P. HABA, M. ATIENZA.

ABSTRACT. The author considers that the criticism which HABA directs at the standard theory of argumentation is right «in most cases», but that he does not take into account certain relevant aspects which would then give it a certain value. SARLO particularly considers the possibility of understanding this theory as an ideal type in a Weberian sense; or starting from the distinction between context of discovery and context of justification, in order to rescue at least a certain dimension of "argumentative rationality». Apart from this, SARLO agrees with HABA with regard to the possibility and advisability of «having a theory of argumentation in a descriptive/explanatory sense». In his opinion, the main epistemic obstacle to this lies in the «intellectual laziness» of many academics who are unwilling to «reflect upon their own reality, as is demanded by a legal theory sensitive to the facts"

Keywords: legal argumentation, E. P. HABA, M. ATIENZA.

* Fecha de recepción: 9 de mayo de 2011. Fecha de aceptación: 13 de mayo de 2011.

Esta nota tiene su petit histoire, que debe ser consignada aquí. El 20 de enero de 2010, mi amigo y colega E. P. HABA me envió - como suele hacer desde hace años- uno de sus largos artículos de largo título de la larga serie crítica que viene desarrollando: «Razones para no creer en la actual Teoría (ilusionista) de la Argumentación. Papel que tales teorizaciones cumplen como más nueva ideología de legitimación con respecto, especialmente, al discurso jurídico profesional». Ese mismo día le envié unas observaciones críticas muy primarias, que, como suele suceder, Enrique tomó con gran entusiasmo. A partir de allí, se fue tejiendo una trama polémica con M. ATIEnZA, en la cual Enrique se las arregló para incluirme. Pero claro, aquellas rápidas líneas e-pistolares, debían «arreglarse un poco» como me pidió Enrique, a los efectos de su eventual inclusión en una sección de Doxa. Por consiguiente, éstas siguen siendo unas observaciones críticas dirigidas a Enrique, manteniendo el estilo casi coloquial, con algunos desarrollos más prolijos, y unas mínimas referencias. Ello se justifica porque es sólo un episodio de un intenso intercambio e-pistolar que mantenemos con Enrique desde hace más de quince años, originado en los ya lejanos tiempos en que unos admirables cursillos que dictara en Montevideo en 1993 y 1994 me ayudaron a «despertar del sueño dogmático»; cursillos admirables por su erudición, claridad y agudeza crítica, que renovó en su última visita del año 2006. La reelaboración de este comentario sólo se debe a la insistencia de Enrique y a la amable invitación de Manolo para que lo concretase.

** Catedrático de Filosofía y Teoría del Derecho en la Universidad de la República (Uruguay). 


\section{INTRODUCCIÓN}

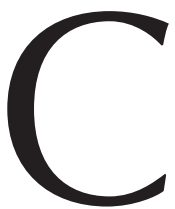

omo recordarás, en mi primer comentario decía que «tu crítica de la llamada "teoría estándar (de la argumentación)" resulta acertada en la mayoría de los casos, pero me parece que desatiende aspectos relevantes que permiten reivindicar cierto valor suyo:

1. No consideras (más que como una hipótesis descartable) la posibilidad de entenderla como un tipo ideal weberiano, en cuyo caso podrías criticarla como mal construida. Arrancas directamente a criticar la intención disimuladora o encubridora, sin considerarla (caridad interpretativa) como tipo ideal.

2. No consideras la distinción entre contexto de descubrimiento y contexto de justificación a propósito de los discursos jurídicos prácticos. Si aceptamos esta distinción, entonces vemos que siempre se exige una fundamentación y que podemos distinguir la calidad de unas argumentaciones, independientemente de cuál sea la intención o la motivación del abogado o juez. Para esa tarea de crítica de la justificación (especialmente en tribunales de alta jerarquía, que se suponen de alta racionalidad) es necesario contar con esquemas racionales para analizarlos críticamente, ¿si no, qué queda? ¿Sólo podremos juzgar intenciones o intereses? Si no rescatamos una cierta dimensión (por más débil que sea) de racionalidad argumentativa para la crítica, entonces la distinción entre derecho y política (o economía) queda desvirtuada».

En lo que sigue desarrollaré un poco más esas observaciones críticas sobre tu crítica a la «teoría estándar de la argumentación» (en adelante: TEA) ${ }^{1}$, sólo para darte la oportunidad de precisar mejor tu crítica, y mantener afilada la espada! ${ }^{2}$.

Según entiendo, tu crítica contra la TEA se concreta en las siguientes afirmaciones:

a) La TEA consiste en «teorizaciones pseudodescriptivas con respecto a los razonamientos jurídicos», aunque reconoce que «no dejan de hacer referencia [...] a ciertos aspectos que efectivamente suelen formar parte de los discursos jurídicos». La TEA examinaría el pensamiento jurídico en su dimensión semántica, desdeñando una dimensión pragmática, que — precisamente - permitiría apreciar que «las realidades psicosociales que en la práctica condicionan, decisivamente, la producción de los discursos desempeñados por los operadores jurídicos», que son «esencialmente retóricocontingente, basados en falacias del Síndrome normativista».

b) La TEA es «una nueva ideología de legitimación para las formas con que el gremio de los juristas desempeña sus discursos [...] en los tribunales [...] tomando el lugar de la forma silogística», aunque reconoces, con todo, que constituye «una caracterización señaladamente menos simplista que la del silogismo judicial».

En lo que sigue, trataré de especificar qué aspectos encuentro criticables de tu ensayo, y por qué.

${ }^{1}$ Esta sigla representa, además, una bella metáfora: bien podría ser que ese emprendimiento teórico (TEA) simbolice la función paradojal de las «teas»: astilla resinosa que, encendida, sirve para iluminar, pero en la misma medida se consume por el fuego.

2 De aquella nota original dejaré de lado mis observaciones a tu periodización de la obra de PERELMAN, por considerarlo ahora fuera de interés; en su lugar, te remito copia de mi viejo trabajo sobre PERELMAN de 1994. 


\section{EN CUANTO AL STATUS EPISTÉMICO DE LA TEA}

\subsection{Sobre la caracterización de la denominada TEA}

Como blanco de tu crítica tomas la TEA, según la caracterización que hiciera ATIENZA, en la cual efectivamente parece predominar una concepción basada en los supuestos racional-idealistas de TOULMIN, ALEXY, etc.; en esa constelación de ideas, si bien es cierto que no hay un lugar para trabajos como los de LAUTMANN o SCHEUERLE —-según tu conocimiento de estos autores-, cabe reconocer que no se deja de señalar los intereses cognitivos que debería satisfacer una teoría de la argumentación aún por hacerse.

Esto quiere decir que —en puridad — la TEA no pretende — más allá de utilizar la denominación de «teoría»- ser una teoría en sentido explicativo o descriptivo. ATIENZA, en nombre de esa constelación de pensadores, parece fundamentalmente interesado en adoptar un punto de vista crítico o político, más allá de todos los esfuerzos analíticos.

Si así fueran las cosas, entonces pierde sentido tu crítica de la TEA como teoría, pues ésta no pretende — al menos en la perspectiva elegida — ser una teoría científica: no da cuenta o se interesa por la realidad sino por la calidad de la argumentación. Más aún: la propia TEA niega (punto 5 de la caracterización de ATIENZA) la distinción entre una perspectiva teórica (punto de vista externo) y las propias prácticas profesionales que se quieren teorizar, para abrazar una concepción ideal de la argumentación. De esta manera, tu crítica, al tomar como parámetro tu concepción de una teoría de la argumentación, podría incurrir en una suerte de reduccionismo epistémico.

\subsection{La TEA como «tipo ideal»}

Ahora bien, el hecho que la TEA en la versión dominante se incline por una concepción ideal-racional de la argumentación con fines críticos, no imponía ésa como la única interpretación posible. En efecto, la caracterización que hace ATIENZA de la TEA es suficientemente abierta (comprende una vasta gama de aportes, aunque es cierto, no los realistas que señalas), problematizada (no deja de plantear muchas tensiones internas) y dinámica (la muestra como un programa inacabado) permitiría interpretar que allí están las bases de un tipo ideal en sentido weberiano.

En su lugar, vos partís de una de las posibles interpretaciones de la supuesta «teoría», la que resulta más vulnerable a la crítica. Habrá que esperar hasta el parágrafo 9 de tu escrito («Excurso: distintas funciones discursivas de lo ideal») para que nos presentes otras posibles interpretaciones de las propuestas de la TEA. Pues bien, yo pienso que bien podrías haber explorado - como una alternativa igualmente válida y en competencia- el interpretar buena parte de los logros de la TEA como un tipo ideal en sentido weberiano.

No estoy improvisando una opinión sobre esto, ya que cuando años atrás estudié la obra de PERELMAN, me planteé su status epistémico, y allí llegué a la conclusión que 
desde una perspectiva epistémica, la mejor forma de entenderla era como un tipo ideal weberiano $^{3}$. Bajo esta óptica, las elaboraciones englobadas bajo el rótulo de TEA podrían considerarse como aportes a ese tipo ideal.

\subsection{Sobre el carácter de «racionalización escapista» de la TEA}

Es indudable - $\mathrm{y}$ vos lo reconoces- que los autores incluidos en la TEA han aportado refinamientos categoriales y refinamientos conceptuales que enriquecen a una teoría de la argumentación. Desde esta perspectiva, las críticas a la TEA resultarían exageradas y no harían justicia a sus aportes positivos.

Yo parto de la base que entendemos las acciones que cumplen los abogados y jueces (juristas en contextos institucionales) como acciones dotadas de sentido, esto es, no son meramente reactivas. El «sentido» aquí significaría —según WEBER- el mentado y subjetivo de los sujetos de la acción, queriendo significar con ello que se trata de acciones comprensibles (de acciones locas o incomprensibles, no nos ocuparíamos). Si no suponemos alguna racionalidad en los actores, pues entonces ya no sólo sería imposible teorizar, sino siquiera hablar de ello.

Como bien sabes, porque sos un estudioso de WEBER, el tipo ideal, se elabora «acentuando unilateralmente uno o varios puntos de vista y encadenando una multitud de fenómenos aislados, difusos y discretos, que se encuentran en gran o pequeño número, y que se ordenan según los precedentes puntos de vista elegidos unilateralmente para formar un cuadro de pensamiento homogéneo». No obstante, «el tipo ideal como tal no tiene que corresponder con ninguna "realidad": es solamente un instrumento para conocer la realidad».

Como decía WEBER, el tipo ideal designa un conjunto de conceptos que el especialista de las ciencias humanas forma con el único fin de la investigación, es el modo de formar conceptos propios del método histórico o individualizante, el cual tiene por objeto estudiar la realidad y los fenómenos en su singularidad, combinando así los juicios históricos individualizantes y los enunciados generales.

Pero también destaca WEBER que los tipos ideales carecen de validez absoluta, sino que «en razón de la variación inevitable de las ideas de valor rectoras, no puede haber conceptos históricos verdaderamente definitivos, a modo de fin último general, sino que debe admitirse que, teniendo en cuenta que al formarse conceptos rigurosos y unívocos para el punto de vista singular que orienta el trabajo, cabe percibir cada vez claramente los límites de su validez». Esto me permitirá luego formular algunas consideraciones sobre contexto de descubrimiento del modelo.

Viene bien, además, recordar que para WEBER la fijación de «cómo se hubiera desarrollado esa acción de haberse conocido todas las circunstancias y todas las intenciones de los protagonistas y de haberse orientado la elección de los medios —a tenor de los datos de la experiencia considerados por nosotros como existentes- de un

3 Ó. SARLO, «La teoría de la argumentación o Nueva Retórica de Perelman», en AA.VV., Hermenéutica y racionalidad, Montevideo, FCU, 1994, 95. 
modo rigurosamente racional con arreglo a fines, es el criterio que hace posible luego la imputación de las desviaciones a las irracionalidades que las condicionan. [...] La construcción de una acción rigurosamente racional con arreglo a fines sirve en estos casos a la sociología — en méritos de su evidente inteligibilidad y, en cuanto racional, de su univocidad-como un tipo (tipo ideal), mediante el cual comprender la acción real, influida por irracionalidades de toda especie (afectos, errores), como una desviación del desarrollo esperado de la acción racional».

Y todavía nos advierte WEBER: «Este procedimiento no debe, pues, interpretarse como un prejuicio racionalista de la sociología, son sólo como un recurso metódico; y mucho menos, por tanto, como si implicara la creencia de un predominio en la vida de lo racional. Pues nada nos dice en lo más mínimo hasta qué punto en la realidad las acciones reales están o no determinadas por consideraciones racionales de fines (no puede negarse la existencia del peligro de interpretaciones racionalistas en lugares inadecuados. Toda experiencia confirma, por desgracia, este aserto)» (Economía y sociedad, 7).

Lo que quiero significar es que entendida de esta manera - caridad interpretativa- la teoría de la argumentación constituye (en el caso de PERELMAN) o sienta las bases de (en el caso de la TEA) un tipo ideal de las acciones argumentativas, en especial, las que se cumplen en contextos judiciales.

Sólo a partir de un tipo ideal de ese estilo estamos en condiciones de juzgar críticamente las prácticas argumentativas. ¿Cómo podríamos decir que un juez no justificó el fallo o que su justificación es irracional? $\mathrm{O}$, más aún, ¿cómo podríamos simplemente decir que está argumentando? Si no presuponemos algún ideal de racionalidad, no estaríamos en condiciones de comprender las acciones realizadas, y en especial no estaríamos en condiciones de criticarlas.

\subsection{Sobre el carácter racionalizante de la TEA}

Vistas así las cosas, entonces se me aparece claro que tu crítica hubiera sido más productiva si la hubieras centrado no ya sobre el carácter «ideal» de las propuestas, sino sobre las estrategias en conflicto en la base de la teorización de la argumentación jurídica. En efecto, la construcción de un campo teórico - y de los tipos ideales que permitan su manejo- supone adoptar algunas decisiones estratégicas (interés cognoscitivo/valorativo) de carácter pre-teórico. En este sentido, creo que está la disputa más importante para una auténtica teoría de la argumentación y los tipos ideales que permitirían orientarse en su estudio: o suponemos que la racionalidad de la argumentación jurídica gira en torno a criterios de corrección moral (ALEXY y la TEA) o de racionalidad instrumental (eficacia retórica, PERELMAN).

No me voy a detener ahora a discutir este punto, pero me parece que éste debería ser - y parece estar en la base de tu preocupación - el centro de la discusión; pero desde ya quiero señalar que a mi juicio esto no puede resolverse analizando los discursos jurídicos aisladamente, sino en el marco de una teoría institucional del Derecho. 
En esta confrontación, tiendo a estar de acuerdo contigo: creo que una auténtica teorización (comenzando por la construcción de un tipo ideal) debería partir de la base que las disputas judiciales no giran en torno a una corrección (o racionalidad) moral abstracta y total, sino en torno al logro de decisiones razonadas, justificadas en términos institucionales, en el marco de una indudable discrecionalidad interpretativa (tópica) de los tribunales. Ésta es la imagen a la cual llega PereLman en su Traité, y que me parece una buena base de teorización. Pero, más allá de las disputas pre-teóricas del medio europeo, creo que los tipos ideales deben construirse — como recomendaba WEBER - interpretando contextos individuales e históricamente situados. En materia social no podemos universalizar fácilmente.

\subsection{Sobre el carácter idealizante (pseudodescriptivo o poco pragmático) de la TEA}

En tu artículo señalas con insistencia —nunca está de más— la falta de compromiso con los hechos que trasunta la TEA.

Pero, una vez más, hay que ser cuidadoso - y caritativo en términos interpretativos- en la crítica, porque el proceso de teorización no implica necesariamente que el teorizador — incluyendo a quien formula el tipo ideal — se ocupe de realizar investigación empírica: es suficiente que las categorías utilizadas en la teorización sean útiles para «ver» o «distinguir» mejor algunos aspectos de la realidad, que de todas maneras es también —-me refiero a «la realidad»— una construcción discursiva, al menos en buena medida.

Pero además, no debe descartarse que en muchos casos los autores de la TEA analizan casos paradigmáticos, para corroborar aspectos de su teoría, al menos, su rendimiento crítico.

Entonces, la crítica me parece exagerada, porque la cuestión sería ésta: ¿la TEA aporta categorías de análisis útiles para escudriñar las prácticas argumentativas en el derecho? Y ello independientemente de que sus autores hayan hecho o no investigación empírica. Personalmente diría decididamente que sí. Muchas de las categorías analíticas aportadas por los argumentativistas son de enorme utilidad para el estudio, la crítica - y hasta para la práctica- de las argumentaciones reales. Al respecto me bastaría con hacer referencia a experiencias personales.

a) En al menos un caso importante y difícil, pude elaborar un argumento novedoso recurriendo a una de las estrategias descritas por PERELMAN para el manejo de la realidad. En ese caso — que ameritó una discusión doctrinaria luego- no me creí que hubiera ganado el juicio «gracias a la teoría de la argumentación» o «gracias a que el tribunal se comportó racionalmente» o por haber aceptado que «se trataba de una cuestión de corrección moral» tal como parece suponer la TEA; nada de eso. Lo único que digo es que en un caso difícil, la teoría de la argumentación me permitió (o facilitó) armar una argumentación que a su vez facilitó al tribunal encontrar una salida justificada, cuando todos los precedentes estaban en contra. Sin esas herramientas teóricas, no me hubiera sido tan sencillo hacerlo. Puedo decir, además, que los demás abogados que actuaban en mi equipo me confesaron que no se les hubiera ocurrido la salida 
propuesta. El conocimiento de las teorías y de los tipos ideales sirve, además, para eso: saber cómo funcionan las «conexiones de sentido» entre premisas, para descubrir falacias (o para generarlas hábilmente) en la práctica, etcétera.

b) Puedo decir, además, que la teoría de la argumentación me ha permitido realizar críticas de jurisprudencia de un nivel más sofisticado que el habitual en la dogmática. Mostrar unas premisas ocultas, o una contradicción en las premisas, etc., es un arma formidable, a condición de que exista un auditorio que valore y comprenda la racionalidad argumental. Es obvio que no siempre ello se da en la realidad, pero en el long term, comportarse irracionalmente tiene también sus costos. Criticar la racionalidad de unos fallos importantes no significa que de hecho y siempre los tribunales puedan ser total y absolutamente racionales, pero ésa es una de las maneras de hablar intersubjetivamente sobre cuestiones debatibles.

c) Finalmente una experiencia en el campo de la investigación académica. Entre los años 2006-2007 se desarrolló en mi Facultad un proyecto de investigación denominado «Análisis sobre la racionalidad técnica y argumentativa del discurso parlamentario en torno al tema de la despenalización del aborto» ${ }^{4}$, en el cual actué como consultor y para ello recomendé utilizar como categorías para el análisis de contenido, algunas extraídas de la teoría de ALEXY, entre otras. Ello permitiría «observar» cuáles eran los intereses en juego, las ideologías dominantes, las irracionalidades que afloran aquí y allá, etc. Sin esas herramientas teóricas, el análisis de los debates parlamentarios no habrían pasado de un relato de las discusiones, hubiera sido sencillamente imposible extraer conclusiones más ilustrativas, bajo el supuesto — claro— de que existe un modelo racional de comportamiento argumental.

\section{ALGUNAS «FALACIAS DE GENERALIZACIÓN» EN LA CRÍTICA}

Sin entrar en detalles, estimo que tu crítica incurre en generalizaciones falaciosas, que creo poder señalar en varios sentidos.

\subsection{No distingue, o destaca debidamente, los logros analíticos de la TEA}

En efecto, la TEA comprende muchas cosas: una cierta concepción de la racionalidad práctica, una cierta idea del derecho, unos criterios de corrección, etc. Pero también contiene o aporta una serie de categorías analíticas que pueden resultar de gran interés teórico, y que son relativamente independientes o independizables de aquellos supuestos básicos de la TEA. Esto vos mismo lo reconoces, «en letra chica», digamos.

Para mencionar sólo un ejemplo: la distinción entre justificación interna y justificación externa (en cualesquiera de sus versiones) permite comprender mejor la distinción entre casos fáciles y casos difíciles. Y por ahí, podemos tener una guía sensata para saber cómo (o criticar cuando) se argumenta en dichos casos. Por ejemplo, podríamos

${ }^{4}$ Proyecto financiado por la Comisión Sectorial de Investigación Científica (CSIC) de la Universidad de la República, Alicia Castro (responsable), y equipo integrado por Gonzalo Calviño, Marcela Vigna y Constanza Farfalla, finalizado en marzo de 2007. 
encontrar ridículo que para rechazar la registración de un instrumento notarial o impugnar una multa por cruzar un semáforo en rojo (actos básicamente técnicos), un abogado invocase el derecho natural o argumentase moralmente. Que los jueces tomen esto en cuenta o no, no invalida la herramienta analítica si queremos orientarnos acerca de cómo argumentar o criticar a quienes lo hacen de manera poco racional. La distinción entre casos fáciles y difíciles puede basarse en razones estructurales, morales o lingüísticas, pero no cabe duda que —empíricamente- los sistemas jurídicos funcionan gracias a que «de hecho» sus operadores tienen presente o intuyen todo el tiempo esas dos categorías. Y por lo tanto, toda herramienta conceptual que nos permita orientar esa distinción, es teóricamente relevante, independientemente que sea utilizada conscientemente en la práctica.

\subsection{No distingue entre los diversos contextos prácticos de la argumentación}

Al postular radicalmente la inutilidad o falsedad de la TEA, no tomas en consideración las diferencias relevantes que — a mi juicio- existen entre las prácticas judiciales de los distintos tribunales. En otras palabras: ¿es igual la «realidad» forense de un tribunal rural en Uruguay o Perú, que un tribunal constitucional europeo o la Corte de La Haya? O sea: ¿existe la misma distancia epistémica (grado de corrrespondencia) entre la TEA (en su dimensión representativa) y esas prácticas judiciales?

Me parece que tu crítica no repara en esa diferente racionalidad que creo se da en los extremos de la larga gama de tribunales que hoy existen en el mundo.

Si hemos de dar razón a la teoría de la racionalidad en general (que vos mismo has desarrollado con erudición y claridad) o a la teoría de la argumentación de PERELMAN en particular, es claro que la racionalidad de los argumentos es una variable dependiente del grado de intersubjetividad que exista en la comunidad argumentativa o al menos en el auditorio. En este sentido, entonces, se impondría reconocer que existen auditorios dotados de una racionalidad $\mathrm{alta}^{5}$. Como seguramente recordarás, el propio WEBER señalaba que la «racionalidad» de los cálculos matemáticos descansan en «hábitos mentales» (Economía y sociedad, 6). Por consiguiente, no es descabellado pensar —más bien ésa es la evidencia- que existen ámbitos institucionales integrados por personas con un alto entrenamiento y propensión a reaccionar ante argumentos bien hechos.

El origen de esta falacia se origina — a mi modo de ver- en que no hayas tomado en consideración el contexto de descubrimiento de la TEA ${ }^{6}$ : ésta se produce en $-\mathrm{y}$ está motivada por- el contexto de actuación de los tribunales constitucionales europeos, y en especial la Corte Constitucional alemana, que ALEXY toma como laboratorio

5 Entendiendo por tal cosa, por ejemplo: cuerpos de expertos (abogados y magistrados) con un alto consenso o acuerdo intersubjetivo acerca de la conceptualización de los hechos (uso del lenguaje descriptivo) o los criterios de validez normativo (regla de reconocimiento), y sensibles a las conexiones de sentido semántico entre premisas formuladas lingüísticamente.

6 Te aclaro que aquí utilizo la distinción entre contexto de descubrimiento y contexto de justificación en el sentido propio en que se utiliza en epistemología, y no en el sentido análogo en que lo hace la propia TEA. Aquí sólo quiero distinguir entre las motivaciones y circunstancias contextuales e históricas que explican la formulación de una TEA qua teoría. 
experimental. Estos tribunales están integrados por jueces de una alta racionalidad, que son capaces de desarrollar argumentaciones con pretensiones de racionalidad muy completa o mucho más completa de lo que podría o estaría en condiciones de hacer —o podría exigírsele a - un tribunal ordinario, sin preparación y acuciado por cientos de expedientes, como ocurre en Latinoamérica, sin ir más lejos.

Por cierto que comparto las críticas en cuanto al efecto enmascarador o ilusionista que cumple la TEA en contextos ajenos al que le dio origen, pero, en ese caso, la responsabilidad, ¿es de los autores o de los difusores y receptores que descontextualizan la TEA? Pienso que esto demandaría un estudio más detenido para poder juzgar con evidencias más sólidas.

\subsection{No mira el problema en una perspectiva histórica}

Encuentro que tu crítica radical no toma en cuenta la dialéctica o interacción histórica que puede existir entre unos modelos ideales (incluso normativos) y las prácticas correspondientes.

Aún si tomamos en consideración la dimensión pragmáticamente normativa o encomiástica (en su «peor» versión) de la TEA, de lo cual sin duda algo tiene, tu crítica incurre en la falacia de aislar a la TEA de una perspectiva histórica ${ }^{7}$. Ejemplificando: podemos estar de acuerdo en que los principios y derechos fundamentales proclamados en 1789 o todavía en 1948 eran fantasiosos o idealistas, pero ¿podemos afirmar tajantemente que no provocaron ningún resultado virtuoso en el devenir histórico?

Entonces: ¿Podemos afirmar sic et simpliciter que la «ideología racionalista» no tendrá consecuencias racionalizantes en las prácticas judiciales? Para esto, nuevamente, me parece que es necesario moverse con prudencia, y realizar investigaciones empíricas, debidamente contextualizadas, tomando series históricas largas, comparando prácticas de distintas épocas, etcétera.

De un modo intuitivo, tiendo a creer que la humanidad ha evolucionado en el sentido de una judicialización del mundo de la vida, y que en ese marco, las prácticas judiciales han evolucionado sensiblemente. Pienso que la aparición de un nuevo tipo de jurisdicción de alta racionalidad - la jurisdicción internacional, la comunitaria y la constitucional - integrada con expertos de gran jerarquía académica, dotados de un estatuto que garantiza un grado de independencia inimaginable en épocas anteriores, o actualmente en contextos ordinarios, muestran una evolución nada desdeñable en lo que vos llamas «la realidad». Pensar que la realidad judicial anterior a la II Guerra Mundial era igual o mejor que la actual, me parece que es no registrar un cambio significativo. Y si estuviéramos de acuerdo en ello, no cabría negar la posibilidad de que esa

7 Viene a mi mente la opinión de un racionalista como POPPER, quien admitía que inclusive las teorías filosóficas, aparentemente irrefutables o dogmáticas, podían someterse a un examen crítico desde la racionalidad falsacionista, preguntándose si sus consecuencias prácticas eran beneficiosas o no (Conjeturas y refutaciones, Paidós, 1983, 63 y 244). Por consiguiente, no basta con señalar el carácter idealista o dogmático de una concepción, sino que cabría discutir - mediante evidencia empírica — su inutilidad o perversidad práctica para el conocimiento o el progreso de una determinada ciencia. 
evolución se profundizase. Es más: cabría pensar que una teoría de la argumentación bien administrada haya tenido que ver y pueda seguir incidiendo en esa evolución.

El problema, en tal caso, se trasladaría a otra cuestión: la racionalización que promociona la TEA (situación ideal de habla o diálogo libre de presiones), ¿es deseable o no?, ¿podemos avanzar sensiblemente hacia ella o no?, ¿'es sustentable o no?, ¿avanzaría mejor por la vía de meras idealizaciones o requiere de más investigación empírica? lo cual ya es otro tema, que no discutes y que tampoco yo lo haré ahora.

\section{CONCLUSIÓN}

He procurado - no sin esfuerzo- encontrar puntos poco claros, insuficientes o poco justificados en tu crítica, con la esperanza que ello te permita fortalecer tu argumentación.

$\mathrm{Al}$ igual que vos, pienso que es posible y conveniente disponer de una teoría de la argumentación en sentido descriptivo/explicativo. Para ello precisamos construir un tipo ideal, que sólo podrá partir de una comprensión convincente de las prácticas reales.

En ese camino, creo que hay mucho camino hecho y aportes valiosísimos en la TEA, pero el gran obstáculo epistémico viene siendo - creo- la pereza intelectual de muchos académicos, más prestos a repetir modelos europeos acríticamente, que reflexionar sobre su propia realidad, como demandaría una teoría jurídica sensible a los hechos. 